\title{
Long term trends in prevalence of neural tube defects in Europe: population based study
}

\begin{abstract}
Babak Khoshnood, ${ }^{1}$ Maria Loane, ${ }^{2}$ Hermien de Walle, ${ }^{3}$ Larraitz Arriola, ${ }^{4}$ Marie-Claude Addor, ${ }^{5}$ Ingeborg Barisic, ${ }^{6}$ Judit Beres,, Fabrizio Bianchi, ${ }^{7}$ Carlos Dias, ${ }^{9}$ Elizabeth Draper, ${ }^{10}$ Ester Garne, ${ }^{11}$ Miriam Gatt, ${ }^{12}$ Martin Haeusler, ${ }^{13}$ Kari Klungsoyr, ${ }^{14}$ Anna Latos-Bielenska, ${ }^{15}$ Catherine Lynch, ${ }^{16}$ Bob McDonnell, ${ }^{17}$ Vera Nelen, ${ }^{18}$ Amanda J Neville, ${ }^{19}$ Mary T O'Mahony, ${ }^{20}$ Annette Queisser-Luft, ${ }^{21}$ Judith Rankin, ${ }^{22}$ Anke Rissmann,, ${ }^{23}$ Annukka Ritvanen, ${ }^{24}$ Catherine Rounding,, ${ }^{25}$ Antonin Sipek, ${ }^{26}$ David Tucker, ${ }^{27}$ Christine Verellen-Dumoulin, ${ }^{28}$ Diana Wellesley, ${ }^{29}$ Helen Dolk ${ }^{2}$
\end{abstract}

\section{ABSTRACT}

\section{STUDY QUESTION}

What are the long term trends in the total (live births, fetal deaths, and terminations of pregnancy for fetal anomaly) and live birth prevalence of neural tube defects (NTD) in Europe, where many countries have issued recommendations for folic acid supplementation but a policy for mandatory folic acid fortification of food does not exist?

\begin{abstract}
METHODS
This was a population based, observational study using data on 11353 cases of NTD not associated with chromosomal anomalies, including 4162 cases of anencephaly and 5776 cases of spina bifida from 28 EUROCAT (European Surveillance of Congenital Anomalies) registries covering approximately 12.5 million births in 19 countries between 1991 and 2011. The main outcome measures were total and live birth prevalence of NTD, as well as anencephaly and spina bifida, with time trends analysed using random effects Poisson regression models to account for heterogeneities across registries and splines to model non-linear time trends.

SUMMARY ANSWER AND LIMITATIONS

Overall, the pooled total prevalence of NTD during the study period was 9.1 per 10000 births. Prevalence of NTD fluctuated slightly but without an obvious
\end{abstract}

\section{WHAT IS ALREADY KNOWN ON THIS TOPIC}

Peri-conceptional supplementation with folic acid can greatly reduce the risk of neural tube defects (NTD)

Although various recommendations for folic acid supplementation have been issued in Europe and elsewhere, important barriers exist for effective implementation of these recommendations

In contrast, mandatory fortification of food staples with folic acid has proved very effective in decreasing the prevalence of NTD

Up to date, population based data on the long term trends of the prevalence of NTD in Europe, where policies for mandatory fortification do not exist, are not available and could help to inform future policies

\section{WHAT THIS STUDY ADDS}

The prevalence of NTD has not decreased in Europe despite longstanding recommendations aimed at promoting peri-conceptional folic acid supplementation and the existence of voluntary folic acid fortification Policies for mandatory fortification of food staples with folic acid should be considered as an important and more effective means for prevention of NTD in Europe downward trend, with the final estimate of the pooled total prevalence of NTD in 2011 similar to that in 1991. Estimates from Poisson models that took registry heterogeneities into account showed an annual increase of $4 \%$ (prevalence ratio 1.04, 95\% confidence interval 1.01 to 1.07) in 1995-99 and a decrease of $3 \%$ per year in 1999-2003 (0.97, 0.95 to 0.99), with stable rates thereafter. The trend patterns for anencephaly and spina bifida were similar, but neither anomaly decreased substantially over time. The live birth prevalence of NTD generally decreased, especially for anencephaly. Registration problems or other data artefacts cannot be excluded as a partial explanation of the observed trends (or lack thereof) in the prevalence of NTD.

WHAT THIS STUDY ADDS

In the absence of mandatory fortification, the prevalence of NTD has not decreased in Europe despite longstanding recommendations aimed at promoting peri-conceptional folic acid supplementation and existence of voluntary folic acid fortification.

FUNDING, COMPETING INTERESTS, DATA SHARING The study was funded by the European Public Health Commission, EUROCAT Joint Action 2011-2013. HD and $M L$ received support from the European Commission DG Sanco during the conduct of this study. No additional data available.

\section{Introduction}

Neural tube defects (NTD) are a major group of severe congenital anomalies that are associated with substantial mortality, morbidity, and long term disability, as well as emotional, psychological, and economic costs. ${ }^{12}$ Each year, approximately 5000 fetuses in Europe are affected with NTD. Most of these cases are diagnosed prenatally, and termination of pregnancy for fetal anomaly is by far the most common outcome for fetuses with NTD. ${ }^{3-5}$

Convincing evidence shows that peri-conceptional folic acid supplementation can substantially decrease the prevalence of NTD. ${ }^{6-8}$ Whereas many countries in Europe have issued recommendations for folic acid supplementation for women of reproductive age, or specifically for those who intend to become pregnant, mandatory fortification programmes do not yet exist in Europe. ${ }^{9}$ A previous study found that in the past these recommendations had not had an appreciable effect on the prevalence of NTD in European countries. ${ }^{10}$ A more 
recent but preliminary analysis of the pooled data on the prevalence of NTD in the European Surveillance of Congenital Anomalies (EUROCAT) network suggested that their overall prevalence may have slightly decreased in the period 2004-08. ${ }^{5}$

Most population based congenital anomaly registries in Europe belong to the EUROCAT network (www. eurocat-network.eu/), with a common database. In 2009 EUROCAT published a special report on NTD, ${ }^{9}$ which showed that important barriers continue to exist for successful implementation of the recommendations for folic acid supplementation. Hence, only a small minority of women take folic acid supplements in the peri-conceptional period as recommended..$^{112}$

In this study, we assessed the trends in the total prevalence and live birth prevalence of NTD in Europe by using data from EUROCAT registries for the period 19912011. We examined trends for all NTD combined, as well as separately for anencephaly and spina bifida, the most common forms of NTD.

\section{Methods}

\section{Data sources}

Since 1980, the EUROCAT central database has held individual anonymised records of cases of congenital anomaly occurring for full member registries and aggregate data for associate member registries, including live births, fetal deaths from 20 weeks gestational age, and termination of pregnancy for fetal anomaly. Information on each of the registries, including methods of case ascertainment and local procedures regarding ethics approval for the registries' activities and their collaborations with EUROCAT, are available on the EUROCAT website (www.eurocat-network.eu/ABOUTUS/MemberRegistries/MembersAndRegistryDescriptions/AllMembers) and in the publication by Greenlees et al. ${ }^{13}$ All registries use ICD-9 (international classification of diseases, 9th revision) or ICD-10 with BPA extension to code up to nine syndrome or malformation codes for each case.

All cases that were not associated with a chromosomal anomaly and had a diagnostic code corresponding to a neural tube defect (ICD-9 740 -742 and ICD-10 Q00, Q01, Q05) were included for full and associate EUROCAT registries that could provide data from both the 1990s and the 2000s; most registries provided data for the entire, or almost the entire, time period between 1991 and 2011 (table 1). We extracted data on 11353 cases of NTD, including 4162 cases of anencephaly (ICD-9 740 and ICD-10 Q00), 5776 cases of spina bifida (ICD-9 741 and ICD-10 Q05), and 1415 cases of encephalocele (ICD-9 7420 and ICD-10 Q01), from 28 registries in 19 countries covering approximately 12.5 million births, in October 2013 for the analysis of time trends in total and live birth prevalence of NTD between 1991 and 2011.

\section{Patient involvement}

No patients were involved in setting the research question or the outcome measures; nor were they involved in design and implementation of the study. There are no plans to involve patients in dissemination.

\section{Data analysis}

We plotted the time trends, during the period 1991 to 2011, in the total and live birth prevalence of all non-chromosomal NTD and separately for anencephaly and spina bifida. We defined total prevalence of NTD as the total number of cases of NTD (live births plus fetal deaths after 20 weeks of gestational age plus termination of pregnancy for fetal anomaly) per 10000 total births (live births plus fetal deaths). We defined live birth prevalence as the number of live births with NTD per 10000 live births. We examined the plots of time trends in total and live birth prevalence of NTD by using restricted cubic splines, ${ }^{14} 15$ which can provide a flexible, semi-parametric, continuous model of the relation between prevalence of NTD and time.

Using the number of births as the "exposure" variable, we then used random effects Poisson regression models to examine the annual trends in the prevalence of NTD, for all NTD combined and separately for anencephaly and spina bifida. We used random effects models to take into account any heterogeneity that may exist across the registries. ${ }^{16} 17$ In the Poisson models, we used linear splines (or "piece-wise exponential models") for modelling the time trends in the prevalence of NTD; we used splines with five equally spaced knots based on the quintiles of the distribution of the time period to estimate separately the annual trends for the following time periods: $1991-95,1995-99,1999-2003,2003-07$, and 2007-11. We used Stata software (versions 11 and 13) for all analyses.

\section{Results}

\section{Trends in total prevalence of NTD}

Figure 1 shows the time trend in the total prevalence of non-chromosomal NTD for the period 1991-2011, using pooled data from all of the EUROCAT registries included in the study and with time trends modelled with restricted cubic splines. The total prevalence of NTD was 9.1 (95\% confidence interval 8.9 to 9.3) per 10000 for 1991-2011 (table 1), fluctuating between a maximum of approximately 10.1 (highest) per 10000 in the period 1999-2003 and 8.5 (lowest) per 10000 in the period 2003-07 (fig 1). Overall, the total prevalence of NTD in 2011 was comparable to that in 1991. Time trend patterns in the pooled prevalence of anencephaly and spina bifida were comparable to those for all NTD combined.

Table 2 shows the results of random effects Poisson regression models that take into account heterogeneities across registries in estimating the time trends. Estimates are presented as prevalence ratios and can be interpreted as percentage increase (for ratios $>1$ ) or percentage decrease (for ratios $<1$ ). The estimates suggest that the total prevalence of NTD increased by about 4\% a year between 1995 and 1999 (prevalence ratio 1.04, $95 \%$ confidence interval 1.01 to 1.07 ), decreased by $3 \%$ in 1999-2003 (0.97, 0.95 to 0.99), and was fairly stable thereafter.

For non-chromosomal anencephaly, a slight increase was apparent in the 1990s, which was offset by a $4 \%$ decrease between 2003 and 2007 (prevalence ratio 0.96, 
뜽

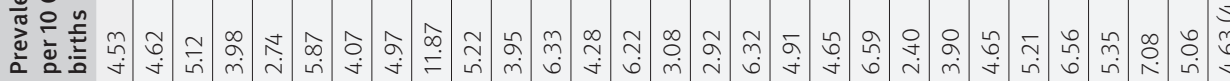

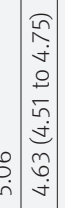

$\frac{\text { m }}{3}$

そo

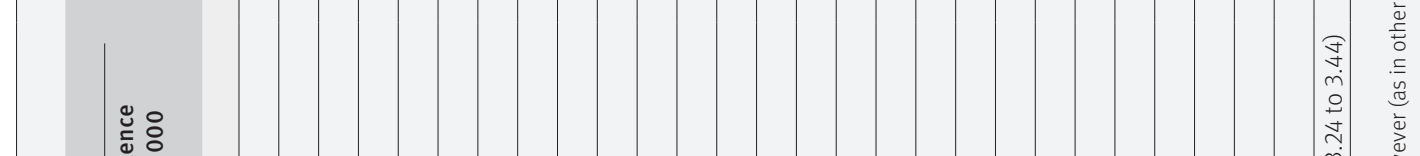

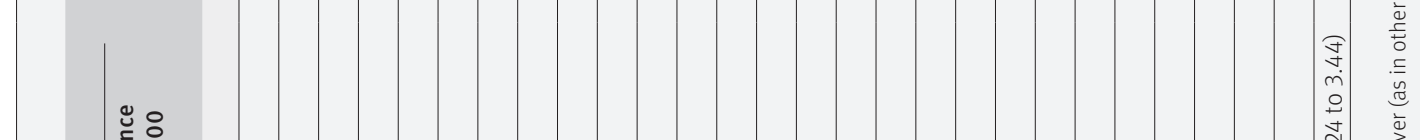

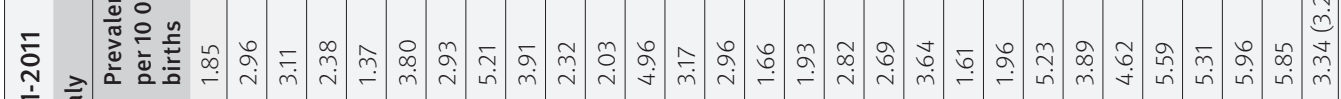

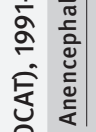

垔

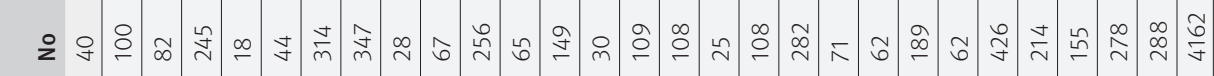

政

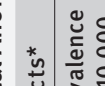

0
$:$

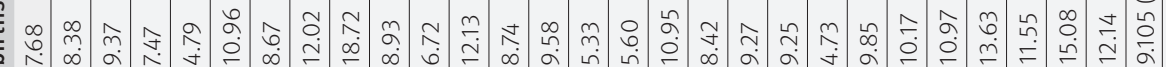

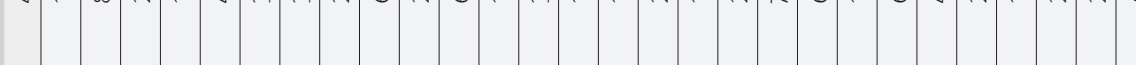



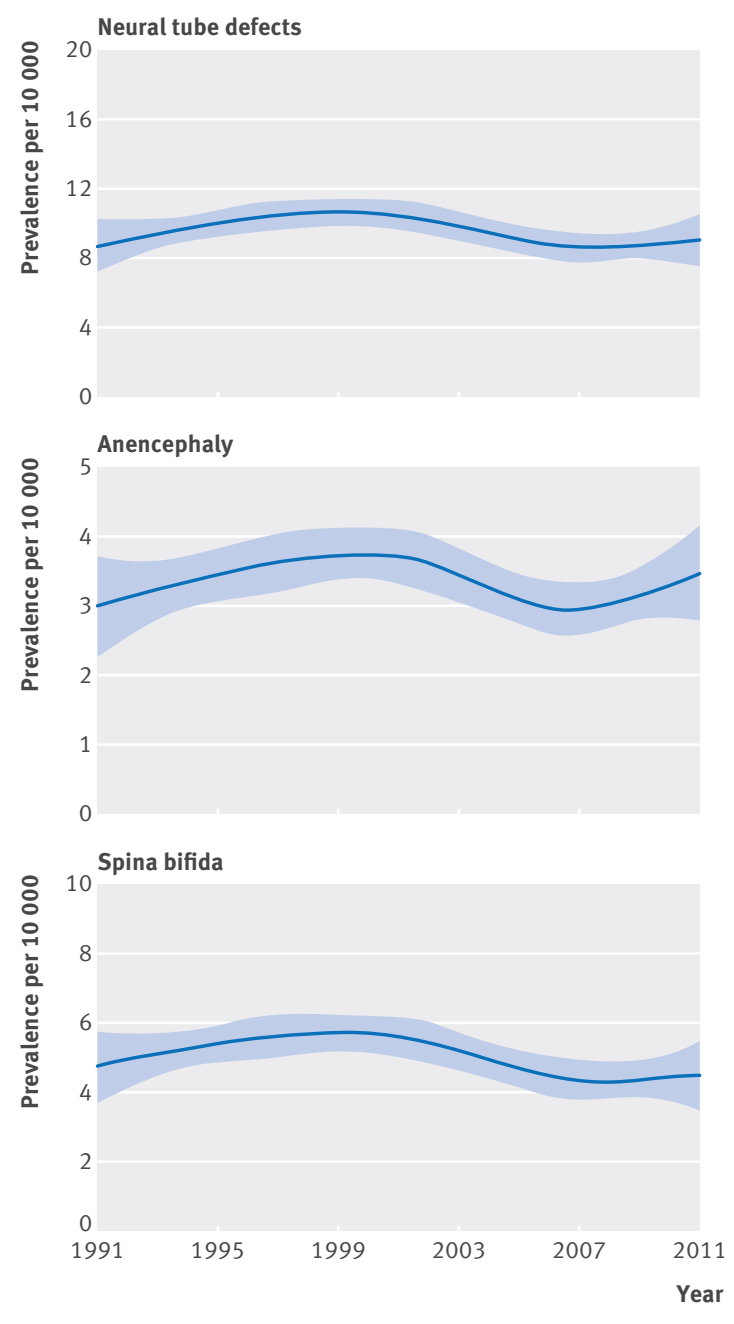

Fig 1 | Trends in total prevalence of non-

chromosomal neural tube defects in Europe,

1991-2011: restrictive cubic spline estimates of pooled data in EUROCAT registries
0.93 to 0.99), with stable rates afterwards until 2011. For non-chromosomal spina bifida, trends in the total prevalence mirrored those for overall NTD noted above (table 2).

\section{Trends in live birth prevalence of NTD}

Live birth prevalence of NTD was less than half of all cases of NTD and decreased substantially over the study period (fig 2). Estimates from the random effects Poisson models suggested that the decrease occurred more during the 1990s (table 2), once heterogeneities across registries were taken into account. Estimates from the random effects Poisson models also suggested that trends in live birth prevalence of spina bifida were similar to those for all NTD, whereas for anencephaly greater decreases were seen in the live birth prevalence, including a large decrease in the most recent period of 2007-11 equivalent to a $13 \%$ annual decrease (prevalence ratio 0.87, 0.76 to 1.00 ), compared with a stable total prevalence of anencephaly during the same period.

\section{Discussion}

Using data for more than 11000 cases of non-chromosomal neural tube defects from 28 population based
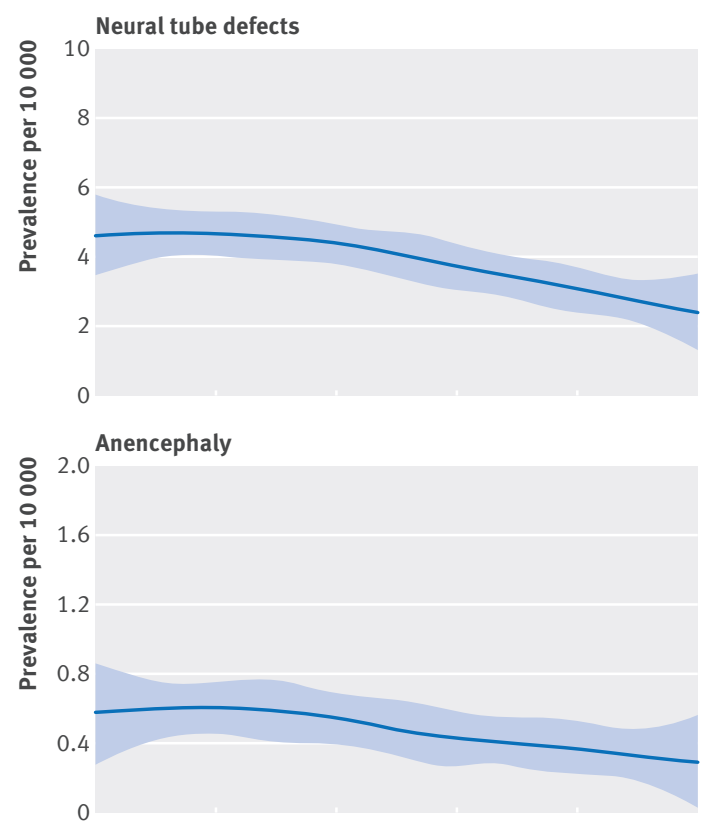

Table 2 | Random effects Poisson regression models with splines (piece-wise exponential models) of trends in total and live birth prevalence of non-chromosomal neural tube defects, anencephaly, and spina bifida in 28 member registries in EUROCAT, 1991-2011

\begin{tabular}{|c|c|c|c|c|}
\hline \multirow[b]{2}{*}{ Time period } & \multicolumn{2}{|l|}{ Total prevalence } & \multicolumn{2}{|l|}{ Live birth prevalence } \\
\hline & $\begin{array}{l}\text { Annual prevalence } \\
\text { ratio }(95 \% \mathrm{CI})\end{array}$ & P value* & $\begin{array}{l}\text { Annual prevalence } \\
\text { ratio }(95 \% \mathrm{Cl})\end{array}$ & $P$ value* \\
\hline \multicolumn{5}{|c|}{ All neural tube defects } \\
\hline $1991-95$ & 0.98 (0.95 to 1.02$)$ & \multirow{5}{*}{$<0.001$} & 0.93 (0.88 to 0.98$)$ & \multirow{5}{*}{$<0.001$} \\
\hline 1995-99 & 1.04 (1.01 to 1.07$)$ & & 0.97 (0.93 to 1.01$)$ & \\
\hline 1999-2003 & 0.97 (0.95 to 0.99) & & 0.96 (0.93 to 1.00$)$ & \\
\hline 2003-07 & 0.99 (0.97 to 1.01$)$ & & 0.97 (0.93 to 1.00$)$ & \\
\hline $2007-11$ & 0.99 (0.97 to 1.01$)$ & & 0.98 (0.93 to 1.02$)$ & \\
\hline \multicolumn{5}{|l|}{ Anencephaly } \\
\hline $1991-95$ & 1.01 (0.95 to 1.07$)$ & \multirow{5}{*}{$<0.001$} & 0.93 (0.80 to 1.09) & \multirow{5}{*}{$<0.001$} \\
\hline 1995-99 & 1.03 (0.99 to 1.08$)$ & & 1.00 (0.89 to 1.13$)$ & \\
\hline 1999-2003 & 0.98 (0.95 to 1.02$)$ & & 0.91 (0.82 to 1.00$)$ & \\
\hline 2003-07 & 0.96 (0.93 to 0.99$)$ & & 0.99 (0.89 to 1.09$)$ & \\
\hline 2007-11 & 1.01 (0.98 to 1.05$)$ & & $0.87(0.76$ to 1.00$)$ & \\
\hline \multicolumn{5}{|l|}{ Spina bifida } \\
\hline $1991-95$ & $0.97(0.92$ to 1.02$)$ & \multirow{5}{*}{$<0.001$} & 0.94 (0.88 to 1.00$)$ & \multirow{5}{*}{$<0.001$} \\
\hline 1995-99 & $1.04(1.00$ to 1.07$)$ & & $0.96(0.92$ to 1.01$)$ & \\
\hline 1999-2003 & 0.97 (0.94 to 1.00$)$ & & 0.97 (0.93 to 1.01$)$ & \\
\hline 2003-07 & 0.99 (0.96 to 1.01$)$ & & 0.96 (0.93 to 1.00$)$ & \\
\hline 2007-11 & 0.99 (0.96 to 1.03$)$ & & $1.00(0.95$ to 1.05$)$ & \\
\hline
\end{tabular}

${ }^{*} \mathrm{P}$ value tests statistical significance of any trend. In this case, significant $\mathrm{P}$ values indicate statistically significant non-monotonic trend for total prevalence and downward trend for live birth prevalence of neural tube defects, anencephaly, and spina bifida.

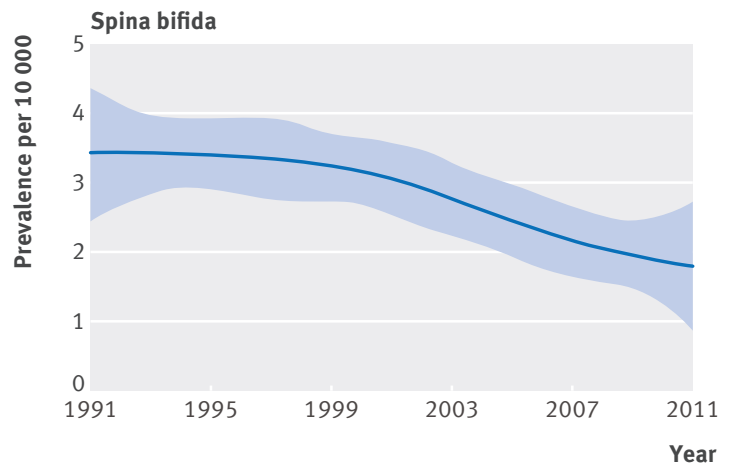

Fig 2 Trends in live birth prevalence of non-chromosomal neural tube defects in Europe, 1991-2011: restrictive cubic spline estimates of pooled data in EUROCAT registries 
registries in 18 countries covering approximately 12.5 million births in Europe over the period 1991 to 2011, we found that the overall (pooled) total prevalence of NTD in 2011 was fairly similar to that in 1991 ( 9 per 10000 births). This was also true for the two main types of NTD, anencephaly and spina bifida, each of which accounts for approximately half of the cases of NTD. Whereas estimates from mixed models that took into account heterogeneities across registries suggested that a small decrease ( $\sim 3 \%$ per year) in total prevalence of NTD between 1999 and 2003, this decrease followed a period of a comparable increase between 1995 and 1999. Overall, we found no clear evidence of a downward trend over the 20 year study period. In contrast, as a result of prenatal diagnosis and termination of pregnancy for fetal anomaly of most NTD in Europe, their live birth prevalence substantially decreased over time, especially for anencephaly.

\section{Strengths and limitations of study}

This was a large study looking at long term trends in the prevalence of NTD based on data from a number of population based registries in Europe. We took into account heterogeneities across registries by using random effects models. Nevertheless, we cannot exclude the possibility that registration problems or other data artefacts may be a partial explanation of the observed trends (or lack thereof) in the prevalence of NTD. However, we had no a priori reason to believe that any changes in registrations would have occurred in specific periods of time in a way that would explain the observed, long term time trends in our study.

\section{Comparisons with other studies}

Our results are consistent with those of an older study of trends in the prevalence of NTD in Europe. ${ }^{10}$ The overall long term fluctuations in the total prevalence of NTD in our data cannot be due to mandatory fortification of food staples, as such a policy has not yet been implemented in European countries. ${ }^{9}$ Voluntary fortification or the various recommendations issued for folic acid supplementation for women of reproductive age in European countries may have had an effect, ${ }^{91819}$ even if small and as yet very little documented, on the intake of folic acid and thereby the prevalence of NTD. ${ }^{91218}$ However, the available evidence points to very low uptake of folic acid supplementation in European countries. ${ }^{11} 12$

In any case, this was an ecological study and, even if folic acid is known to be an important factor for explaining trends in NTD, it is not the only possible reason for any changes in NTD over time. Changes in other risk factors of NTD (for example, maternal smoking ${ }^{20-22}$ and changes in the incidence and management of maternal chronic health conditions, such as obesity, diabetes, and epilepsy, or psychiatric illnesses treated with anti-epileptic drugs that are known to be associated with a higher risk of NTD, ${ }^{23-25}$ as well as any changes in population characteristics (for example, owing to immigration), ${ }^{2}$ must also be considered as possible explanations for the observed fluctuations in the prevalence of NTD.

\section{Conclusions and policy implications}

Our results underscore the fact that 20 years after publication of the Medical Research Council study, ${ }^{6}$ which provided definitive evidence for the efficacy of folic acid in preventing NTD, and years after various recommendations have been issued to promote folic acid supplementation to ensure adequate peri-conceptional folate concentrations for pregnant women, Europe has failed to implement an effective policy for prevention of NTD by folic acid.

NTD represent one of the most prevalent group of birth defects with serious consequences for newborns and their families. Although termination of pregnancy for fetal anomaly has considerably reduced the live birth prevalence of these anomalies, it is certainly not an optimal solution for a birth defect that is highly preventable with a readily available and low cost measure, as is the case for NTD with folic acid supplementation or food fortification. Consumption of adequate natural folates should also be encouraged but in many countries will not raise folate concentrations sufficiently and is likely to leave vulnerable populations unprotected.

Our data suggest that recommendations, voluntary fortification, or both have not been effective in decreasing the prevalence of NTD in Europe. Hence, policies for mandatory fortification of food staples with folic acid should be considered as an important and more effective means for prevention of NTD, ${ }^{826}$ while weighing the evidence for its proven benefits and possible risks. ${ }^{219}$

\section{AUTHOR AFFILIATIONS}

'Obstetrical, Perinatal and Pediatric Epidemiology Research Team, Center for Biostatistics and Epidemiology, INSERM U1153, Maternité de Port-Royal, 75014 Paris, France

2EUROCAT Central Registry, Centre for Maternal, Fetal and Infant Research, Institute of Nursing Research, University of Ulster, Newtownabbey, UK

${ }^{3}$ EUROCAT Northern Netherlands Registry, University of Groningen, University Medical Center Groningen, Department of Genetics, Groningen, Netherlands

4 Public Health Division of Gipuzkoa, Instituto BIO-Donostia Basque Government CIBER Epidemiología y Salud Pública - CIBERESP, San Sebatian, Spain

5Service de Genetique Medicale Maternite, CHUV, Lausanne, Switzerland

${ }^{6}$ Children's University Hospital of Zagreb, Clinical Hospital Sisters of Mercy, Zagreb, Croatia

${ }^{7}$ National Institute of Health Development, Department of Hungarian Congenital Abnormality Registry and Surveillance, Budapest, Hungary ${ }^{8} \mathrm{CNR}$ Institute of Clinical Physiology and Tuscany Registry of Congenital Defects, “Gabrielle Monasterio” Foundation, Pisa, Italy

${ }^{9}$ Instituto Nacionale de Saude Dr. Ricardo Jorge, Lisbon, Portugal

${ }^{10}$ Department of Health Sciences, University of Leicester, Leicester, UK ${ }^{11}$ Hospital Lillebaelt, Kolding, Denmark

${ }^{12}$ Department of Health Information and Research, Guardamangia, Malta

${ }^{13}$ Medical University of Graz, Graz, Austria

${ }^{14}$ Medical Birth Registry of Norway, Norwegian Institute of Public Health and Department of Global Public Health and Primary Care, University of Bergen, Bergen, Norway

${ }^{15}$ Department of Medical Genetics, University of Medical Sciences, Poznan, Poland

${ }^{16}$ Public Health Department, HSE South, Lacken, Kilkenny, Ireland

${ }^{17}$ Health Service Executive, Dublin, Ireland 
${ }^{18}$ Provincial Institute for Hygiene, Antwerp, Belgium

19Registro IMER - IMER Registry (Emilia Romagna Registry of Birth Defects), Center for Clinical and Epidemiological Research, University of Ferrara, Ferrara, Italy

${ }^{20}$ Department of Public Health, Health Service Executive - South, Ireland

${ }^{21}$ Birth Registry Mainz Model, Childrens Hospital, University Medical Center, Johannes Gutenberg-University, Mainz, Germany

${ }^{22}$ Institute of Health and Society, Newcastle University, Newcastle, UK ${ }^{23}$ Malformation Monitoring Centre Saxony-Anhalt, Medical Faculty Otto-von-Guericke University, Magdeburg, Germany

${ }^{24}$ National Institute for Health and Welfare, Helsinki, Finland

${ }^{25}$ National Perinatal Epidemiology Unit, University of Oxford, Oxford, UK

${ }^{26}$ National Registry of Congenital Anomalies of the Czech Republic, Department of Medical Genetics, Thomayer University Hospital, Prague, Czech Republic

${ }^{27}$ Public Health Wales, Swanseaa, UK

${ }^{28} \mathrm{Center}$ for Human Genetics, Institut de Recherche Scientifique en Pathologie et en Génétique, Charleroi, Belgium

${ }^{29}$ University Hospitals Southampton, Faculty of Medicine and Wessex Clinical Genetics Service, Southampton, UK

Contributors: BK, HdW, ML, and HD conceived the study. BK did the statistical analysis, with the assistance of ML, and wrote the first draft of the article. HD, ML, and HdW made substantial contributions to interpretation of results and revision of the manuscript. All other co-authors were registry representatives from EUROCAT participating registries. They contributed and validated their data and participated in the interpretation of results and critical revision of manuscript. BK and $M L$ are the guarantors.

Funding: The study was funded by the European Public Health Commission, EUROCAT Joint Action 2011-2013 (grant No 201022 04). The funding body had no role in study design, analysis, or reporting.

Competing interests: All authors have completed the ICMJE uniform disclosure form at www.icmje.org/coi disclosure.pdf (available on request from corresponding author) and declare: $H D$ and ML received support from the European Commission DG Sanco during the conduct of this study; no financial relationships with any organisations that might have an interest in the submitted work in the previous three years; no other relationships or activities that could appear to have influenced the submitted work.

Data sharing: No additional data available.

Transparency: The lead authors (the manuscript's guarantors) affirm that the manuscript is an honest, accurate, and transparent account of the study being reported; that no important aspects of the study have been omitted; and that any discrepancies from the study as planned (and, if relevant, registered) have been explained.

This is an Open Access article distributed in accordance with the Creative Commons Attribution Non Commercial (CC BY-NC 4.0) license, which permits others to distribute, remix, adapt, build upon this work non-commercially, and license their derivative works on different terms, provided the original work is properly cited and the use is noncommercial. See: http://creativecommons.org/licenses/by-nc/4.0/.

1 Botto LD, Moore CA, Khoury MJ, Erickson JD. Neural-tube defects. N Engl / Med 1999:341:1509-19.

2 Dunlap B, Shelke K, Salem SA, Keith LG. Folic acid and human reproduction-ten important issues for clinicians. J Exp Clin Assist Reprod 2011;8:2.

3 Garne E, Loane M, Dolk H, et al. Prenatal diagnosis of severe structural congenital malformations in Europe. Ultrasound Obstet Gynecol 2005;25:6-11

4 Boyd PA, Devigan C, Khoshnood B, Loane M, Garne E, Dolk H. Survey of prenatal screening policies in Europe for structural malformations and chromosome anomalies, and their impact on detection and termination rates for neural tube defects and Down's syndrome. BJOG 2008;115:689-96.
5 Khoshnood B, Greenlees R, Loane M, Dolk H. Paper 2: EUROCAT public health indicators for congenital anomalies in Europe. Birth Defects Res A Clin Mol Teratol 2011:91 (suppl 1):S16-22.

6 MRC Vitamin Study Research Group. Prevention of neural tube defects: results of the Medical Research Council Vitamin Study. Lancet 1991;338:131-7.

7 Czeizel AE, Dudas I. Prevention of the first occurrence of neural-tube defects by periconceptional vitamin supplementation. N EnglJ Med 1992:327:1832-5.

8 Oakley GP Jr. The scientific basis for eliminating folic acid-preventable spina bifida: a modern miracle from epidemiology. Ann Epidemiol 2009;19:226-30

9 EUROCAT Folic Acid Working Group. EUROCAT special report: prevention of neural tube defects by folic acid supplementation in Europe. 2009. www.eurocat-network.eu/content/Special-Report-NTD3rdEd-Part-I.pdf.

10 Busby A, Abramsky L, Dolk H, Armstrong B. Preventing neural tube defects in Europe: population based study. BMJ 2005;330:574-5.

11 Bestwick JP, Huttly WJ, Morris JK, Wald NJ. Prevention of neural tube defects: a cross-sectional study of the uptake of folic acid supplementation in nearly half a million women. PLoS One 2014;9:e89354

12 Tort J, Lelong N, Prunet C, Khoshnood B, Blondel B. Maternal and health care determinants of preconceptional use of folic acid supplementation in France: results from the 2010 National Perinatal Survey. BJOG 2013;120:1661-7.

13 Greenlees R, Neville A, Addor MC, et al. Paper 6: EUROCAT member registries: organization and activities. Birth Defects Res A Clin Mol Teratol 2011;91 (suppl 1):S51-100.

14 Royston P. A strategy for modelling the effect of a continuous covariate in medicine and epidemiology. Stat Med 2000;19:1831-47.

15 Sauerbrei W, Royston P, Binder H. Selection of important variables and determination of functional form for continuous predictors in multivariable model building. Stat Med 2007:26:5512-28

16 Rankin J, Pattenden S, Abramsky L, et al. Prevalence of congenital anomalies in five British regions, 1991-99. Arch Dis Child Fetal Neonatal Ed 2005:90:F374-9.

17 Loane M, Dolk H, Garne E, Greenlees R, EUROCAT Working Group Paper 3: EUROCAT data quality indicators for population-based registries of congenital anomalies. Birth Defects Res A Clin Mol Teratol 2011:91 (suppl 1):S23-30.

18 Hoey L, McNulty H, Askin N, et al. Effect of a voluntary food fortification policy on folate, related B vitamin status, and homocysteine in health adults. Am / Clin Nutr 2007:86:1405-13.

19 Flynn MA, Anderson WA, Burke SJ, Reilly A. Session 1: Public health nutrition. Folic acid food fortification: the Irish experience. Proc Nutr Soc 2008;67:381-9.

20 Hackshaw A, Rodeck C, Boniface S. Maternal smoking in pregnancy and birth defects: a systematic review based on 173687 malformed cases and 11.7 million controls. Hum Reprod Update 2011:17:589-604.

21 Mladovsky P, Allin S, Masseria C, Hernandez-Quevedo, McDaid D, Mossialos E. Health in the European Union: trends and analysis. World Health Organization, 2009: 76-81 (Observaotry Studies Series No 19)

22 Lelong N, Blondel B, Kaminski M. [Smoking during pregnancy in France between 1972 to 2003: results from the national perinatal surveys]. J Gynecol Obstet Biol Reprod (Paris) 2011:40:42-9.

23 Jentink J, Bakker MK, Nijenhuis CM, Wilffert B, de Jong-van den Berg LT. Does folic acid use decrease the risk for spina bifida after in utero exposure to valproic acid? Pharmacoepidemiol Drug Saf 2010;19:803-7.

24 Jentink J, Loane MA, Dolk H, et al. Valproic acid monotherapy in pregnancy and major congenital malformations. N Engl J Med 2010:362:2185-93.

25 Jentink J, Dolk H, Loane MA, et al. Intrauterine exposure to carbamazepine and specific congenital malformations: systematic review and case-control study. BM/ 2010;341:c6581.

26 Honein MA, Paulozzi LJ, Mathews TJ, Erickson JD, Wong LY. Impact of folic acid fortification of the US food supply on the occurrence of neural tube defects. JAMA 2001:285:2981-6.

27 Oakley GP, Mandel JS. Folic acid fortification remains an urgent health priority. BMJ 2004;329:1376.

(c) BMJ Publishing Group Ltd 2015 